\title{
PLANEJAMENTO TRIBUTÁRIO: SALDO CREDOR ICMS NAS EMPRESAS
}

\author{
Clari Schuh ${ }^{1}$ \\ Augusto Caetano Maria² \\ Marco Aurélio Batista de Sousa ${ }^{3}$ \\ Recebido em: 16 mar. 2020 \\ Aceito em: 2 jul. 2020
}

Como citar este artigo: SCHUH, C.; MARIA, A.; SOUSA, M. PLANEJAMENTO TRIBUTÁRIO:

SALDO CREDOR ICMS NAS EMPRESAS. Revista Visão: Gestão Organizacional, v.9, n.1, p.100-

119. DOI: https://doi.org/10.33362/visao.v9i1.2195

Resumo: O Imposto sobre Operações Relativas à Circulação de Mercadorias e sobre Prestação de Serviços de Transporte Interestadual, Intermunicipal e de Comunicação (ICMS), é um dos que mais onera as empresas brasileiras. O acúmulo de saldo credor deste imposto constitui um problema tributário, pois nem sempre conseguem compensar com os débitos de suas operações, pois se trata de um imposto Estadual. Neste contexto, o estudo objetivou investigar qual é a melhor forma de uma indústria de fertilizantes se utilizar do seu saldo credor do ICMS. Em termos metodológicos, o estudo caracteriza-se como uma pesquisa descritiva com abordagem qualitativa do problema. O levantamento dos dados deu-se por meio de documentos disponibilizado pela empresa e a legislação vigente, onde foram levantados os créditos de ICMS dos Estados referente saldo em 2015, que a empresa atual. Após, verificado as opções que a legislação prevê e efetuados os cálculos, analises e projeções necessárias, verificou-se que a opção menos onerosa é vender os créditos de ICMS para terceiros.

Palavras-Chave: Saldo Credor. ICMS. Crédito acumulado. Planejamento tributário.

\section{TAX PLANNING: ICMS CREDIT BALANCE IN COMPANIES}

Abstract: The tax on operations related to the circulation of goods and on the provision of interstate, intermunicipal and communication services (ICMS) is one of the most burdensome Brazillian companies. The accumulation of credit balance of this duty constitutes a tax problem, since not everytime they compensatte with the debts of its operations, because its a state tax. In this contexto, the study aimed to investigate what would be the best way of a fertilizer industry use its ICMS credit balance. The study is marked as a descriptive research with qualitative approach of the situation. The survey of data took place through documents made available by the company and the current legislation where the ICMS credits of the states were gathered, refering to the balance in 2015 , generated by the company. After verifying the options predicted by the legislation and made the necessary calculations, analysis and projections, it was found that the least costly option is to sell ICMS credits to third parties.

Keywords: Credit balance. ICMS. Tax Planning.

\footnotetext{
${ }^{1}$ Universidade de Santa do Sul - UNISC E-mail: clarischuh@unisc.br.

2 Universidade de Santa do Sul - UNISC E-mail: augustomaria@mx2.unisc.br.

${ }^{3}$ Universidade Federal de Mato Grosso do Sul, Campus de Três Lagoas - UFMS E-mail: mcbsousa@bol.com.br.
} 


\section{INTRODUÇÃO}

O Imposto sobre Operações Relativas à Circulação de Mercadorias e sobre Prestação de Serviços de Transporte Interestadual, Intermunicipal e de Comunicação, o ICMS, é um dos que mais onera na composição da carga tributária brasileira e o que tem mais arrecada (GASSEN, ET AL. 2013; PÊGAS, 2017).

Neste contexto, vale destacar que há organizações que contam com crédito acumulado deste imposto junto as Fazendas Estaduais, decorrente do sistema de nãocumulatividade, sistemática prevista na Constituição Federal que permite a compensação do valor devido a título de ICMS na saída com o montante pago nas operações anteriores (BRASIL, 1988; LOZAKAM, 2015; PÊGAS, 2017).

O saldo credor de imposto acumulado se origina de aplicações de benefícios fiscais concedidos pelas Secretarias das Fazendas Estaduais na forma de diferimentos, reduções na base de cálculo, isenções, benefícios fiscais além de alíquotas diferenciadas, conforme previsto no Regulamento do ICMS de cada Estado brasileiro (LOZAKAM, 2015).

Sendo assim, pode-se dizer que diariamente empresas de diversos segmentos acabam por gerar um saldo credor de ICMS em montante maior que os débitos apurados mensalmente, o que, constantemente, gera um acúmulo de crédito escritural (GAIL; BARRETO, 2015).

A permanência deste valor de crédito escritural na conta fiscal da empresa segundo Gail e Barreto (2015), gera um impacto negativo no resultado da empresa, uma vez que a sua baixa perspectiva de realização obriga muitas vezes a reduzir contabilmente esses valores, onerando a empresa e tornando o ICMS um tributo não recuperável na prática. Isso é consequência das limitações e dificuldades que toda empresa enfrenta ao ser obrigado a lidar com diferentes regras criadas pelas Secretarias de Fazendas Estaduais.

Ao exercerem a competência tributária, delegam para o particular uma série de deveres instrumentais quase sempre incompreensíveis ou de difícil execução. A nãocumulatividade do ICMS é sistemática prevista na Constituição Federal, que permite a compensação do valor devido a título de ICMS na saída com o montante pago nas operações anteriores (BRASIL, 1998; GAIL; BARRETO, 2015).

O fato de uma empresa manter em sua escrita fiscal sucessivamente saldo credor acumulado de ICMS, por força de uma legislação que não permite compensação por ocasião das saídas, é uma espécie de confisco, além de onerar e prejudicar seriamente a competitividade destas empresas, pelo aumento de custo que proporciona (LOZAKAM, 2015).

O suposto benefício de não ter a incidência do imposto na saída, acaba se constituindo um problema, vez que as empresas acabam arcando com todo o imposto pago na entrada, sem ter como compensá-lo por ocasião das saídas. O motivo é que se rompe nela o ciclo da não cumulatividade da cadeia produtiva, ficando com o ônus do imposto pago e não compensado, 
o chamado acúmulo de saldo credor acumulado de ICMS em sua escrita fiscal (LOZAKAM, 2015).

Assim, visando à necessidade da empresa em compreender uma forma de reduzir o saldo credor de ICMS, entende-se que necessitam saber como avaliar suas operações e também de que forma aplicar um planejamento tributário eficiente que se constitui em meio legal de elisão fiscal e de projetar o futuro tributário da empresa (REZENDE; PEREIRA; ALENCAR, 2010). Vale destacar que "a elisão fiscal é um ato formal e jurídico, totalmente lícito, para que o contribuinte possa reduzir sua carga tributária, por meio de um ato para antever o fato gerador" (FARIA, 2016, p. 24).

Diante destes comentários este estudo se propõe a investigar qual é a melhor forma de utilizar o saldo credor de ICMS acumulado em uma indústria de fertilizante. Paralelamente a esta atividade, procura evidenciar conceitos relativos ao planejamento tributário na empresa; demonstrar a melhor forma de utilização do saldo credor de ICMS acumulado; e identificar o melhor custo-benefício em relação às operações da entidade.

\section{CONTABILIDADE TRIBUTÁRIA E O ICMS}

A contabilidade tributária é compreendida como um instrumento para mensurar o impacto gerado pelos tributos no patrimônio da entidade. É uma importante ferramenta para gestão de tributos, que consiste na escolha das melhores alternativas de tributação disponíveis na legislação tributária. E, dentre seus objetivos busca o controle e o planejamento dos tributos oriundos das operações e resultados empresariais, além da realização de análises de todas as implicações tributárias de cada transação relevante (OLIVEIRA, 2009; REZENDE; PEREIRA; ALENCAR, 2010; FARIA, 2016; SOUSA, 2018).

Em relação ao Imposto de Circulação de Mercadorias e Serviços (ICMS), Madruga (2015) menciona que o ele desrespeita na prática todas as características de um sistema tributário, citado por Adam Smith, em seu livro Riquezas das Nações, publicado em 1776, a saber: capacidade contributiva dos cidadãos; regras para a fixação dos impostos, evitando-se arbitrariedades; facilidade para os contribuintes; baixo custo do sistema arrecadador e eficiência econômica. Este imposto "desrespeita na prática todas essas características, exceto quanto ao seu resultado arrecadatório. Mesmo assim, encontra sua raiz jurídica em nosso sistema tributário, especialmente na CF/88, art. 155, o qual estabelece a competência aos Estados e ao Distrito Federal para instituí-Io" (MADRUGA, 2015, p. 170).

O ICMS é um tributo de função fiscal, fonte de receita expressiva para os entes da federação, apesar de ser considerado como extrafiscal quando é seletivo, como a alta alíquota do fumo como desincentivo ao seu consumo. Embora tenha uma função fiscal, ele tem sido utilizado como um imposto de finalidades além desta função, quando há muitas isenções, 
reduções de base de cálculo e créditos fiscais presumidos (MACHADO SEGUNDO, 2013; SOUSA, 2018).

Para Madruga (2015), as principais características do ICMS são: Imposto Indireto: contribuinte de fato é o consumidor final; Imposto Real: incide igualmente para todas as pessoas; Imposto seletivo ou não: seletivo em função da essencialidade das mercadorias e dos serviços; Imposto por homologação: seu lançamento é de responsabilidade do contribuinte, ficando sujeito a posterior homologação pela autoridade administrativa; Imposto de incidência multifásica: há a incidência do imposto a cada etapa da circulação até chegar ao consumo final; Imposto não cumulativo: abata-se em cada operação ou prestação o valor incidente na operação ou prestação anterior; Imposto proporcional: seu valor é determinado pela aplicação de uma alíquota sobre uma base de cálculo; Imposto por dentro: a base de cálculo do ICMS contém o valor do próprio imposto. Como consequência dessa última característica, a alíquota efetiva é maior que a estabelecida em lei.

Em relação à incidência deste imposto, ela recai nas operações relativas à circulação de mercadorias, inclusive o fornecimento de alimentação e bebidas em bares, restaurantes e estabelecimentos similares. O termo "circulação de mercadorias" não é propriamente a circulação da mercadoria física, mas a circulação econômica, que é a principal condutora do fato gerador do ICMS e a circulação jurídica, que é a transmissão de posse ou propriedade da mercadoria (MADRUGA, 2015; SOUSA, 2018).

No que refere a sua não incidência, é a ocorrência de fatos que não estão tipificados em leis; portanto, fora do campo da incidência de um tributo e incapazes de gerar uma obrigação tributária (SOUSA, 2018).

Quanto a sua imunidade, trata-se de um fenômeno de natureza constitucional. As normas constitucionais que, direta ou indiretamente, tratam do assunto fixam, por assim dizer, a incompetência de das entidades tributantes para onerar, com exações, certas pessoas, seja em função de sua natureza jurídica, seja porque são coligadas a determinados fatos, bens ou situações (MADRUGA, 2015).

Logo, mesmo dentro do campo de incidência de uma atividade ela é excluída da hipótese de gerar uma obrigação tributária.

Sobre a isenção, Paiva (2013, p. 330), menciona que ela é instituto de natureza jurídica polêmica. Classicamente definida como "hipótese de não incidência legalmente qualificada". Destaca ainda que, a doutrina mais moderna a vem entendendo como norma impeditiva do exercício da competência tributária em certas situações, em razão da mutilação de um ou alguns aspectos da hipótese de incidência.

No que se refere a não-cumulatividade do ICMS ela é sistemática prevista na Constituição Federal no artigo 155, parágrafo 2으, inciso I, que permite a compensação do valor devido a título de ICMS na saída com o montante pago nas operações anteriores. A exceção a 
essa regra reside nos casos de uma saída isenta ou não tributada (BRASIL, 1988).

Quanto a sua base de cálculo ela é especificada em termos matemáticos a hipótese de incidência do tributo, a qual vem exposta pelo art. 13 da Lei Complementar 87/1996 (BRASIL, 1996; PÊGAS, 2017).

Esta base conforme Sousa (2018, p. 15), representa o valor para "apuração do montante do tributo a ser recolhido aos cofres públicos". Integra também a base de cálculo do tributo o valor correspondente a seguro, juros e outras quantias pagas, recebidas ou debitadas, assim como os descontos condicionados (BRASIL, 1996).

Sobre a sua alíquota ela é o percentual determinado por lei que, aplicado à base de cálculo, determina o valor a ser recolhido, podendo variar conforme operações interestaduais, exportações ou operações para dentro do próprio estado (SOUSA, 2018).

A Constituição Federal, em seu art. 155, paragrafo segundo, inciso III, instituiu o princípio da seletividade das alíquotas do ICMS em função da essencialidade das mercadorias e serviços e definiu, no inc. IV, que as alíquotas aplicáveis às operações e prestações interestaduais e de exportação serão estabelecidas pelo Senado Federal. Deste modo, as alíquotas internas não poderão ser inferiores às previstas para as operações interestaduais (BRASIL, 1998).

Para Madruga (2015) e Machado Segundo (2018), os Estados e o Distrito Federal, adotaram como alternativa a essa restrição, a redução da base de cálculo, que se espalhou nas legislações estaduais de todo o país. Com essa redução, aplicando-se a alíquota permitida pela Constituição Federal, a carga tributária é inferior às alíquotas interestaduais.

\section{IMPORTÂNCIA E FINALIDADES DO PLANEJAMENTO TRIBUTÁRIO}

Os tributos servem para regular e possibilitar a vida em sociedade, mediante a contribuição individual de cada pessoa em favor de toda a comunidade. No Brasil, além de comporem uma malha embaraçada de obrigações, os tributos constituem uma tarefa complexa e onerosa e apresentam um perfil de carga de alta influência sobre as atividades produtivas das empresas que crescem a cada ano (FABRETTI, 2006).

O impacto dos tributos que compõem o sistema tributário brasileiro faz com que haja maior ônus financeiro nas transações. Tal Ônus depende da forma de procedimento adotada em cada situação, aliada à utilização de tributos como instrumento de política de desenvolvimento econômico, com a prática de incentivos fiscais (HUCK, 1997).

Segundo Marins (2002), as constantes alterações das normas tributárias criam um campo altamente instável, no qual poucas empresas melhor preparadas têm mais possibilidades de gerar lucros que as restantes. Assim, surge o descompasso econômico no qual empresas sofrem em função da ausência de estrutura para arcar com os custos transacionais 
de determinada região. Por essas razões, o elevado montante de tributos pagos pelas empresas requer um adequado e constante gerenciamento dos gastos ao longo de todo o ano-calendário, não apenas por sua alta carga, mas também por toda estrutura interna que demanda (LOZAKAM, 2015).

Deste modo, Borba (2001 apud Lizote e Lana, 2012, p. 1), citam que "o gerenciamento estratégico das obrigações tributárias torna-se um item fundamental para a sobrevivência das empresas, independente do seu porte ou setor", e assim o "elevado custo tributário existente no Brasil, se não equacionado, pode provocar a extinção do empreendimento". Sobre este assunto, Fabretti (2012, p. 28) chama a atenção para o fato de que o "mau planejamento tributário é redundar em evasão fiscal, que é a redução da carga tributária descumprindo determinações legais e que é classificada como crime de sonegação fiscal".

Portanto, o planejamento tributário deve-se atentar para as ações que estão nos limites da leia buscando estruturar as operações do contribuinte a fim de que os custos com os tributos não seja superior àquele exigido pelo sistema tributário nacional (SOUSA, 2018).

\section{METODOLOGIA DA PESQUISA}

Tendo como base o objetivo deste estudo, a pesquisa foi caracterizada como exploratória e descritiva. Exploratória, buscar mais informações e conhecimentos respeito da temática investigada contemplando assuntos pertinentes ao planejamento tributário e a saldo credor de ICMS nas empresas, utilizando como estratégia a pesquisa bibliográfica que de acordo com Martins e Theóphilo (2016, p. 51) é "necessária à condução de qualquer pesquisa científica" e a documental com base nos documentos disponibilizados pela empresa objeto de estudo, caracterizando-a e descrevendo os principais achados dos resultados (MARCONI; LAKATOS, 2018).

Vale ressaltar que a operacionalidade deste estudo se deu por meio de um estudo de caso realizado em uma indústria química de fabricação de fertilizantes minerais, a qual disponibilizou documentos e relatórios fiscais referentes ao ano de 2015, e que o seu nome não fosse divulgado.

De posse destas informações coletadas nesta empresa, utilizou-se da abordagem qualitativa e quantitativa para destacar e apresentar os principais achados do estudo. Sendo assim, com base no sistema não cumulativo, para apuração de ICMS do ano de 2015, apuramse os créditos permitidos pelas entradas e débitos referentes às saídas, utilizando as alíquotas previstas no regulamento do ICMS e no Código Tributário Nacional. Após foi realizado a compensação dos débitos e créditos, apurando o tributo a recuperar ou recolher. Depois de efetuados os cálculos e apurados os saldos, definiu-se a amostra das unidades do Estado de Minas Gerais, por representarem 45\% do saldo credor de ICMS acumulado, para realização 
deste estudo de caso.

Em seguida, foi estruturado um quadro comparativo da melhor forma de tributação para reduzir o saldo credor de ICMS acumulado, o que possibilitou melhor visualizar e identificar a modalidade de tributação menos onerosa para a empresa, ou ainda, a modalidade com menor acumulo de saldo credor.

Por fim, demonstra-se a importância do planejamento tributário para a empresa, por apresentar as melhores estratégias na redução de custos de forma lícita, que permite a redução ou postergação do tributo, gerando um melhor resultado final.

\section{ANÁLISE DOS DADOS E DISCUSSÃO DOS RESULTADOS}

Fundada em 1905, na Noruega, a empresa objetivo de estudo possui presença mundial, quanta com mais de 12 mil colaboradores e negocia seus produtos para mais de 150 países. No Brasil, a empresa tem sede em Porto Alegre e escritório em São Paulo.

Para atender o segmento agrícola conta com unidades industriais de produção, de granulação e de ensaque de fertilizantes; e unidades industriais de mistura, de ensaque e de distribuição de fertilizantes, com presença nos principais portos e polos de produção agrícola do País. No segmento de soluções ambientais e produtos industriais possui unidades de produção e comercialização.

Seu portfólio de produtos se refere a fertilizantes, que vai desde a mistura de grânulos a produtos especiais, como: foliares e NPK no grânulo, e programas nutricionais ajudam a produzir os alimentos necessários para a crescente população mundial. Para manter a perspectiva de crescimento em longo prazo, as iniciativas de pesquisa e desenvolvimento (P\&D) da Empresa são focadas na agricultura sustentável e na busca por novas soluções ambientais, como: a redução do uso da água, e a aplicação da quantidade precisa de fertilizantes para produzir alimentos saudáveis e de qualidade superior.

Por representarem $45 \%$ dos valores na composição do saldo credor de ICMS acumulado para as unidades do Brasil, foram selecionadas as unidades de Minas Gerais como amostra desta pesquisa, como mostra o Quadro 1 
Quadro 1. Saldo Credor acumulado por Estado

\begin{tabular}{|l|l|l|}
\hline Unidade da Federação & Saldo Credor & Porcentagem \\
\hline Minas Gerais & $49.104 .788,50$ & $45 \%$ \\
\hline Paraná & $22.946 .780,21$ & $21 \%$ \\
\hline Baía & $11.090 .142,94$ & $10 \%$ \\
\hline Goiás & $10.975 .540,77$ & $10 \%$ \\
\hline Espírito Santo & $5.943 .898,79$ & $5 \%$ \\
\hline São Paulo & $5.256 .227,25$ & $5 \%$ \\
\hline Alagoas & $2.531 .439,56$ & $2 \%$ \\
\hline Santa Catarina & $1.341 .951,50$ & $1 \%$ \\
\hline Total & $109.190 .769,52$ & $100 \%$ \\
\hline
\end{tabular}

Fonte: Elaborado pelos autores

Dentro do princípio da não-cumulatividade, no final das operações, quem paga o ICMS é consumidor final, visto que o ICMS de toda a cadeia produtiva do produto está incluso no valor final da mercadoria, porém com a não-cumulatividade o Estado estará recebendo uma parcela do ICMS a cada fase da cadeia produtiva do produto.

Efetuado a escrita fiscal, confrontando os saldos devedores originados pelas vendas, com os créditos originados pelas compras, o saldo sendo devedor, deve ser recolhido a favor do fisco o montante devido aos cofres públicos nos prazos por eles estabelecidos.

Caso esse confronto de débitos e créditos resultar em saldo credor em favor do contribuinte, este saldo é transferido para os meses subsequentes, podendo ser aproveitado nas futuras operações.

A empresa pesquisada por sua vez, gera mensalmente um valor considerável de saldo credor para transferência e uso nos meses subsequentes. No quadro 2, têm-se os valores acumulados de ICMS no exercício de 2015 das unidades desta empresa, o qual representa um valor acumulado de R\$ 107.848.799,27 entre a confrontação de débito e crédito da escrita fiscal.

Sendo assim, este quadro representa a composição da escrita fiscal dos saldos de ICMS da empresa. Primeiramente é apresentado o saldo credor acumulado por todo o período de 2015. 
Quadro 2. - Unidades com saldos credores - dez/2015

\begin{tabular}{|l|l|l|l|}
\hline Unidade & Planta & UF & Saldo credor \\
\hline 0154 & UBA4 & Minas Gerais & $25.518 .527,68$ \\
\hline 0135 & PGU3 & Paraná & $22.946 .780,21$ \\
\hline 0155 & CON1 & Minas Gerais & $14.447 .925,26$ \\
\hline 0152 & BJG1 & Goiás & $10.975 .540,77$ \\
\hline 0119 & LEM1 & Baia & $9.851 .648,07$ \\
\hline 0011 & UBA2 & Minas Gerais & $7.785 .432,38$ \\
\hline 0157 & VIX & Espírito Santo & $5.943 .898,79$ \\
\hline 0147 & CBT3 & São Paulo & $3.216 .025,52$ \\
\hline 0110 & MCZ1 & Alagoas & $2.531 .439,56$ \\
\hline 0158 & SSA & Baía & $1.238 .494,87$ \\
\hline 0137 & JAU1 & São Paulo & $1.035 .809,70$ \\
\hline 0131 & SUM & São Paulo & $1.004 .373,28$ \\
\hline 0153 & UBA3 & Minas Gerais & $763.997,48$ \\
\hline 0128 & UBA5 & Minas Gerais & $546.161,42$ \\
\hline Total & TPS & Minas Gerais & $42.744,28$ \\
\hline
\end{tabular}

Fonte: Elaborado pelos autores

Porém como foi observado, algumas unidades geram saldo devedor de ICMS. Somente no ano de 2015 o total recolhido aos cofres públicos foram de $\mathrm{R} \$ 28.792 .954,61$.

Na sequência é apresentado às unidades com saldos devedores (valores que devem ser pagos as Fazendas Estaduais), demonstrados mensalmente devido o fato em que os saldos devedores são não cumulativos, e devem ser recolhidos aos cofres públicos mensalmente, como evidencia o Quadro 3, representando o primeiro semestre de 2015. 
Quadro 3. Unidades com saldo devedor - 10 Semestre/2015

\begin{tabular}{|c|c|c|c|c|c|c|c|c|}
\hline Unidade & Planta & UF & janeiro/15 & fevereiro/15 & março/15 & abril/15 & maio/15 & junho/15 \\
\hline 0001 & ECPOA & RS & 891,99 & $9.123,86$ & $1.872,79$ & $2.839,75$ & $5.387,88$ & 0,00 \\
\hline 0002 & POA & RS & $249.284,45$ & $607.156,63$ & 0,00 & $205.845,23$ & $423.136,46$ & $268.487,18$ \\
\hline 0013 & RIG & RS & $325.814,00$ & $245.590,67$ & 150,22 & 0,00 & 0,00 & 0,00 \\
\hline 0140 & RIG3 & RS & $318.082,84$ & $731.418,00$ & 0,00 & $152.102,84$ & $205.913,08$ & $145.492,18$ \\
\hline 0141 & CZB1 & RS & $20.164,70$ & $151.598,19$ & $5.229,82$ & $111.510,18$ & $180.175,45$ & $236.384,57$ \\
\hline 0148 & CAN1 & RS & $148.356,52$ & $450.754,07$ & $54.109,74$ & $140.035,20$ & $330.767,34$ & $417.328,01$ \\
\hline 0138 & VIX3 & ES & $21.434,84$ & $32.267,62$ & $40.555,04$ & $10.574,71$ & $12.822,86$ & $6.592,96$ \\
\hline 0129 & SLZ & MA & $422.870,96$ & $142.121,27$ & $155.326,73$ & $245.656,83$ & $397.824,18$ & $592.086,00$ \\
\hline 0156 & ALF1 & MG & $10.875,73$ & $1.100,88$ & 0,00 & 0,00 & 348,49 & 0,00 \\
\hline 0118 & ROO & MT & $19.766,50$ & $6.709,84$ & $79.046,76$ & 0,00 & $9.266,97$ & $5.976,52$ \\
\hline 0162 & ROO4 & MT & $9.187,21$ & 0,00 & $3.290,85$ & 0,00 & 0,00 & $1.118,60$ \\
\hline 0163 & ROO5 & MT & 28,56 & 0,00 & $22.376,21$ & 745,23 & 0,00 & 0,00 \\
\hline 0164 & ROO3 & MT & $35.285,88$ & $3.720,79$ & $10.773,59$ & $11.922,07$ & 183,60 & $7.046,44$ \\
\hline 0028 & OLI & PE & $155.109,80$ & $137.761,22$ & $700.684,06$ & $130.006,18$ & $177.641,39$ & $68.668,92$ \\
\hline 0161 & RIG2 & RS & 0,00 & $565.932,17$ & 0,00 & 0,00 & 0,00 & 0,00 \\
\hline 0149 & BVI1 & PA & 0,00 & 0,00 & 0,00 & $1.407,84$ & 39,77 & $4.028,40$ \\
\hline 0160 & SLZ2 & MA & 0,00 & 0,00 & 0,00 & 0,00 & 0,00 & $43.976,10$ \\
\hline 0150 & BCA1 & PA & $9.179,21$ & $30.587,72$ & $9.428,53$ & 0,00 & $5.261,89$ & 82,58 \\
\hline & Total & $1.746 .333,19$ & $3.115 .842,93$ & $1.082 .844,34$ & $1.012 .646,06$ & $1.748 .769,36$ & $1.797 .268,46$ \\
\hline
\end{tabular}

Fonte: Elaborado pelos autores

O quadro abaixo apresenta a primeira parte do segundo semestre de 2015.

Quadro 4. Unidades com saldo devedor - 2o Semestre/2015 - Parte 1

\begin{tabular}{|l|l|l|l|l|l|l|l|l|}
\hline Unidade & Planta & UF & jul/15 & ago/15 & set/15 & out/15 & nov/15 & dez/15 \\
\hline 0001 & ECPOA & RS & 0,00 & $3.298,57$ & $5.097,97$ & 0,00 & 269,89 & $4.972,43$ \\
\hline 0002 & POA & RS & $445.677,94$ & $395.525,40$ & $2.487 .624,36$ & $550.523,87$ & $307.555,31$ & $603.910,68$ \\
\hline 0013 & RIG & RS & 0,00 & 0,00 & 0,00 & 0,00 & 0,00 & 0,00 \\
\hline 0140 & RIG3 & RS & $109.410,85$ & $166.733,41$ & $758.035,58$ & $169.011,87$ & 0,00 & $682.534,60$ \\
\hline 0141 & CZB1 & RS & 0,00 & $49.887,54$ & $66.801,19$ & $50.963,27$ & $92.387,46$ & $196.043,25$ \\
\hline 0148 & CAN1 & RS & $397.923,26$ & $210.656,75$ & $2.103 .723,36$ & $129.923,40$ & 0,00 & $33.123,30$ \\
\hline 0138 & VIX3 & ES & $15.489,63$ & $27.928,08$ & $79.461,07$ & $72.960,23$ & $93.966,44$ & $86.780,01$ \\
\hline 0129 & SLZ & MA & $713.842,35$ & $936.571,82$ & $792.572,09$ & $1.087 .900,63$ & $885.732,27$ & $928.598,39$ \\
\hline 0156 & ALF1 & MG & 0,00 & 0,00 & 0,00 & $5.376,29$ & 0,00 & $3.159,00$ \\
\hline 0118 & ROO & MT & $12.878,80$ & $40.754,17$ & $20.731,56$ & $628.990,28$ & $179.144,98$ & $22.007,01$ \\
\hline 0162 & ROO4 & MT & 0,00 & 0,00 & 0,00 & 0,00 & 0,00 & 0,00 \\
\hline
\end{tabular}

Fonte: elaborado pelos autores

Posteriormente a continuação do segundo semestre de 2015. 
Quadro 5. Unidades com saldo devedor - 20 Semestre/2015 - Parte 2

\begin{tabular}{|l|l|l|l|l|l|l|l|l|}
\hline Unidade & Planta & UF & jul/15 & ago/15 & set/15 & out/15 & nov/15 & dez/15 \\
\hline 0163 & ROO5 & MT & $31.499,45$ & 0,00 & 439,05 & $1.900,31$ & 0,00 & 0,00 \\
\hline 0164 & ROO3 & MT & $327.408,80$ & $9.681,03$ & $38.944,88$ & $256.136,19$ & 106,15 & $42.448,07$ \\
\hline 0139 & CAS1 & PR & 0,00 & 0,00 & 0,00 & 0,00 & $13.214,39$ & 0,00 \\
\hline 0146 & CAM1 & PR & 0,00 & 0,00 & 0,00 & 0,00 & $160.128,04$ & 0,00 \\
\hline 0028 & OLI & PE & $63.574,76$ & $19.722,04$ & $6.899,40$ & 0,00 & $7.183,33$ & 0,00 \\
\hline 0161 & RIG2 & RS & 0,00 & 0,00 & 0,00 & 0,00 & $27.252,08$ & $191.302,19$ \\
\hline 0149 & BVI1 & PA & 760,56 & 0,00 & 216,35 & 112,11 & 440,08 & 635,15 \\
\hline 0160 & SLZ2 & MA & $109.095,41$ & $1.815,53$ & $110.664,13$ & $132.834,34$ & 0,00 & $30.892,06$ \\
\hline 0150 & BCA1 & PA & $1.223,36$ & $5.740,18$ & $19.836,12$ & $10.121,45$ & $1.287,54$ & $9.275,13$ \\
\hline
\end{tabular}

Fonte: elaborado pelos autores

A empresa desembolsou cerca de $\mathrm{R} \$ 28.792 .954,61$ milhões de reais, mesmo possuindo mais de $\mathrm{R} \$ 100$ milhões de saldo credor de ICMS acumulado.

Quadro 6. Unidades com saldo devedor por UF

\begin{tabular}{|l|l|}
\hline Unidades da Federação & Total por Unidades da Federação \\
\hline Rio Grande do Sul & $16.951 .105,79$ \\
\hline Maranhão & $7.730 .381,09$ \\
\hline Mato Grosso & $1.839 .516,35$ \\
\hline Pernambuco & $1.467 .251,10$ \\
\hline Espírito Santo & $500.833,49$ \\
\hline Paraná & $173.342,43$ \\
\hline Pará & $109.663,97$ \\
\hline Minas Gerais & $20.860,39$ \\
\hline Total & $\mathbf{2 8 . 7 9 2 . 9 5 4 , 6 1}$ \\
\hline
\end{tabular}

Fonte: elaborado pelos autores

Além dessa problemática, de possuir um excessivo acumulo de crédito, existe também o problema do saldo acumulado não sofrer a correção monetária, ficando estagnado no ativo circulante da empresa, não sofrendo correções com a inflação.

Também gera impacto negativo no retorno sobre investimento (ROI), ou seja: quando maior o ativo, menor será o retorno sobre investimento da empresa. Em seguida, será demonstrado as formas de opções com essa problemática. Sendo através de um planejamento tributário eficaz, ou, com transferência de saldo credor de ICMS para terceiros (venda de ICMS para outras empresas estabelecidas em Minas Gerais).

\section{FORMAS DE UTILIZAÇÃO DO SALDO CREDOR DE ICMS}

Verificou-se que o acúmulo de saldo credor de ICMS se constitui em um problema 
financeiro que atinge um leque cada vez maior de empresas brasileiras. Para tratativa dessa problemática, não existem muitas opções para realizar a baixa desse ativo a recuperar.

Ao mesmo tempo em que a Legislação prevê a compensação do imposto com débitos próprios (compensação do debito com crédito das operações próprias), há a opção de transferência do saldo credor acumulado de ICMS a terceiros (venda de créditos).

A Constituição Federal determinada que, caberá a Lei Complementar, disciplinar o regime de compensação do ICMS. Esta lei Complementar 87/96 estabelece que a lei estadual poderá permitir que os saldos credores acumulados poderão ser transferidos nas condições que definir, a outros contribuintes do mesmo Estado. No entanto, não disciplina o regime de compensação conforme Ihe facultou a Constituição de 1988 e sim outorgou esta competência às unidades federativas, as quais por sua vez, poderão e tem agido de modo discricionário, de modo a limitar ou impedir a efetiva fruição dos saldos credores acumulados de ICMS.

Como é facultado a cada Estado legislar sobre as hipóteses de transferência de saldo credor a terceiros e também a forma de utilização desses saldos, de acordo com o expressivo valor de saldo credor de ICMS acumulado do Estado de Minas Gerais referente às operações da empresa, o mesmo foi selecionado para realização do estudo de caso desse trabalho acadêmico.

\section{TRANSFERÊNCIA DE SALDO CREDOR ACUMULADO DE ICMS NO ESTADO DE MINAS GERAIS}

A legislação do Estado de Minas Gerais, permite que contribuintes utilizem saldos credores acumulados de ICMS para a aquisição de máquinas, veículos e equipamentos ou para venda a terceiros.

\section{a) Opção A - aquisição de máquinas, veículos e equipamentos}

Até 31 de janeiro de 2017, a título de pagamento pela aquisição de caminhonete destinada ao transporte exclusivo de carga, com carroceria aberta ou furgão, de caminhão, de trator, de máquina ou equipamento, novos, destinados a integrar o ativo imobilizado da empresa, poderão ser transferidos para estabelecimento industrial fabricante situado neste Estado (MINAS GERAIS, 2015).

A transferência deve ser autorizada mediante regime especial concedido pelo diretor da Superintendência de Tributação, o qual será o responsável em definir as condições, os limites, as parcelas e os respectivos valores.

$\mathrm{Na}$ solicitação do regime especial, o contribuinte interessado informará: a Classificação Nacional de Atividades Econômicas (CNAE) em que se classifica sua atividade; as mercadorias a serem adquiridas, indicando os respectivos valores e classificações na Nomenclatura Brasileira de Mercadorias (NBM/SH); e os fornecedores, com indicação da razão social, e números de inscrição estadual e no CNPJ de cada fornecedor. 
Após a concessão do regime especial, o contribuinte poderá requerer a substituição ou a inclusão de bem no regime especial, devendo este requerimento conter as mesmas informações previstas neste subitem.

Os estabelecimentos fabricantes dos bens, que receberem em transferências os saldos credores acumulados de ICMS como forma de pagamento das vendas realizadas para os produtores rurais, extratores de minério, indústrias ou comerciantes atacadistas, poderão utilizar os respectivos saldos credores para: abatimento, em conjunto com os demais créditos, de débito do ICMS apurado na escrita fiscal, transportando o eventual saldo credor para abatimento no saldo devedor dos períodos subsequentes; e retransferência, desde que autorizado por regime especial concedido pelo diretor da Superintendência de Tributação, observando-se que o crédito recebido em retransferência poderá ser compensado até o limite de 30\% do saldo devedor apurado pelo estabelecimento destinatário.

A empresa que adquirir os bens relacionados no regime especial ficará sujeito ao pagamento do valor do ICMS transferido ou utilizado, com os acréscimos legais devidos, a contar da data da aquisição, caso ocorra uma das seguintes hipóteses: realize a transmissão do bem, a qualquer título, dentro do prazo de 1 ano, contado da data da aquisição; ou não utilize o bem nas atividades operacionais da empresa em seus estabelecimentos no Estado ou, em se tratando de cooperativa de produtores rurais, nas atividades operacionais dos estabelecimentos dos cooperados no Estado.

\section{b) Opção B - Venda de ICMS a terceiros}

O estabelecimento industrial que possuir crédito acumulado de ICMS em razão de entrada de matéria-prima, produto intermediário ou material de embalagem, e da respectiva utilização do serviço de transporte, poderá transferi-lo a outro contribuinte situado no Estado de Minas Gerais, para pagamento de crédito tributário relativo ao ICMS, inclusive multas, juros e demais acréscimos, parcelado ou não, lançado ou espontaneamente denunciado, inscrito ou não em dívida ativa, ajuizada ou não a sua cobrança, exceto em relação ao imposto escriturado em livro fiscal ou informado na DAPI; ou devido pela entrada, no estabelecimento, de mercadoria oriunda de outra unidade da Federação destinada a uso, consumo ou ativo permanente.

O contribuinte detentor original dos créditos acumulados somente poderá transferilos nas hipóteses neles previstas, quando de sua apuração constar saldo credor do imposto há pelo menos 3 períodos consecutivos, observando ainda as seguintes condições: o crédito apropriado em determinado período somente poderá ser transferido ou utilizado a partir do mês subsequente ao de sua apropriação; na hipótese de operação de venda para entrega futura, a transferência do crédito acumulado a ela relacionado somente poderá ocorrer após a efetiva saída da mercadoria para o destinatário; somente poderá transferir, receber em transferência ou utilizar crédito acumulado, o estabelecimento que adotar o regime normal de 
apuração do imposto.

Para a transferência ou a utilização dos créditos acumulados, o contribuinte detentor do crédito acumulado deverá apresentar demonstrativo de crédito acumulado de ICMS à Delegacia Fiscal a que estiver circunscrito, para análise e aprovação. O demonstrativo será preenchido em 2 vias, que terão a seguinte destinação: 1a via - Delegacia Fiscal a que o contribuinte estiver circunscrito, para arquivo; 2a via - contribuinte, depois de visada pela Delegacia Fiscal.

Para a transferência de crédito acumulado, após a autorização do Fisco, o contribuinte detentor original do crédito deverá adotar os seguintes procedimentos: emitir, a cada parcela autorizada no regime especial, Nota Fiscal, modelo 1 ou 1-A, ou NF-e.

Fazendo constar: Natureza da operação: "Transferência de Crédito Acumulado de ICMS"; e no quadro "Dados do Produto", o número, a série, a data e o valor do documento relativo à aquisição do bem;

I. apresentar a Nota Fiscal ao titular da Delegacia Fiscal a que estiver circunscrito para aposição do visto;

II. registrar a nota fiscal no livro Registro de Saídas, nas colunas "Documento Fiscal" e "Observações", lançando nesta o valor da nota fiscal, informando tratar-se de crédito acumulado transferido e o dispositivo legal que ampara a transferência;

III. registrar no livro RAICMS, na coluna "Outros Débitos", o valor registrado na forma prevista no inciso anterior; e na coluna "Observações", o número, a série, a data e o valor da nota fiscal utilizada para transferência e a seguinte informação: "Transferência de crédito acumulado de ICMS nos termos do artigo 27 do Anexo VIII do RICMS"; e

IV. informar no campo 73 do quadro "Outros Créditos/Débitos" da DAPI modelo 1 o valor da transferência.

O contribuinte indicado como destinatário na nota fiscal (recebedor do crédito acumulado) deverá adotar os seguintes procedimentos:

I. registrar a nota fiscal no livro Registro de Entradas, nas colunas "Documento Fiscal" e "Observações", lançando nesta o valor da nota fiscal;

II. registrar no livro RAICMS, na coluna "Outros Créditos", o valor dos créditos recebidos em transferência; e na coluna "Observações", o número, a série, a data e o valor das notas fiscais, os nomes dos remetentes e a informação de que se trata de crédito acumulado do ICMS recebido em transferência; e

III. informar no campo 66 do quadro "Outros Créditos/Débitos" da DAPI modelo 1 o valor recebido em transferência. Conforme estabelecido no regime especial, o contribuinte entregará na Administração Fazendária a que estiver circunscrito demonstrativo das aquisições efetuadas no mês anterior. 


\section{PLANEJAMENTO TRIBUTÁRIO PARA REDUÇÃO DO SALDO CREDOR DE ICMS}

O planejamento tributário é uma alternativa para redução do saldo credor de ICMS acumulado. Com um adequado gerenciamento no faturamento dos produtos, transferindo as vendas das unidades que geram saldo devedor de ICMS, para uma unidade que gere saldo credor, poderá assim, obter a redução do saldo credor de ICMS. Nesta análise e planejamento, deve-se levar em consideração o custo-benefício, em relação aos custos fixos e variáveis versus o deságio que a empresa sofre por realizar a transferência (venda) do saldo credor de ICMS acumulado a empresas terceiras.

Como se pode observar no Quadro 7 as unidades estabelecidas no Rio Grande do Sul efetuam um alto volume de vendas interestaduais, elevando assim o saldo devedor a pagar. A proposta é que essas vendas sejam efetuadas pelas unidades estabelecidas em Minas Gerais, para que assim o saldo credor seja consumido pela operação de venda interestadual.

Quadro 7. Vendas Interestaduais Rio Grande do Sul

\begin{tabular}{|l|l|l|l|l|}
\hline UF destino & Quantidade & Valor_Contab_Item & Valor_tributo_ICMS & ICMS efetivo à pagar \\
\hline MS & $483.646,24$ & $710.117 .334,58$ & $34.829 .171,67$ & $8.707 .292,92$ \\
\hline SC & $221.458,20$ & $285.541 .222,98$ & $24.201 .103,41$ & $6.050 .275,85$ \\
\hline PR & $89.961,97$ & $121.542 .397,47$ & $10.232 .453,57$ & $2.558 .113,39$ \\
\hline GO & $63.024,63$ & $96.057 .941,04$ & $4.810 .308,62$ & $1.202 .577,16$ \\
\hline MT & $70.742,22$ & $92.127 .034,57$ & $4.525 .249,60$ & $1.131 .312,40$ \\
\hline RO & $47.335,00$ & $75.520 .570,02$ & $3.732 .180,78$ & $933.045,20$ \\
\hline RS & $1.446 .467,13$ & $1.794 .622 .307,68$ & $408.526,24$ & $408.526,24$ \\
\hline DF & $2.766,00$ & $4.564 .189,81$ & $223.645,37$ & $55.911,34$ \\
\hline PA & $1.660,00$ & $2.212 .342,22$ & $108.404,76$ & $27.101,19$ \\
\hline SP & 503,65 & $1.483 .087,57$ & $71.902,54$ & $17.975,64$ \\
\hline MG & 240,40 & $631.156,76$ & $37.414,02$ & $9.353,51$ \\
\hline TO & 161,00 & $341.728,00$ & $16.744,68$ & $4.186,17$ \\
\hline PB & 31,00 & $59.148,00$ & $10.55,16$ & $2.513,79$ \\
\hline Total & $2.428 .007,45$ & $3.184 .840 .460,70$ & $83.207 .160,42$ & $21.108 .184,79$ \\
\hline
\end{tabular}

Fontes: Elaborado pelos autores

Como se observa, as vendas interestaduais para o Mato Grosso do Sul; Santa Catarina; Paraná e Goiás superam R\$18 Milhões de reais de ICMS a pagar. Parte deste imposto poderia ser absorvido por Minas Gerais, para que assim, o saldo credor seja consumido e não mais desembolsado por Rio Grande do Sul.

O quadro 8 demostra uma projeção de venda de Minas Gerais para os estados de Mato Grosso do Sul; Santa Catarina; Paraná, e Goiás com a intenção de diminuir o ICMS devedor das unidades do Rio Grande do Sul. Para essa projeção, foi selecionado um produto que a empresa oferece ao mercado. Considerando: Quantidades de venda aconselháveis para o cálculo; Preço 


\section{Médio por tonelada e Alíquota ICMS}

Quadro 8. Projeção Vendas Interestaduais Minas Gerais

\begin{tabular}{|l|l|l|l|l|l|l|l|}
\hline \multicolumn{1}{|c|}{$\begin{array}{c}\text { UF } \\
\text { Origem }\end{array}$} & \multicolumn{1}{|c|}{$\begin{array}{c}\text { UF } \\
\text { Destino }\end{array}$} & \multicolumn{1}{|c|}{ Quant. } & $\begin{array}{c}\text { Preço } \\
\text { Médio- } \\
\text { Tonelada }\end{array}$ & $\begin{array}{c}\text { Valor } \\
\text { Total }\end{array}$ & $\begin{array}{c}\text { Base de cálculo } \\
\text { ICMS (Valor } \\
\text { Total* 70\%) }\end{array}$ & $\begin{array}{c}\text { Alíquota } \\
\text { ICMS }\end{array}$ & \multicolumn{1}{|c|}{ ICMS } \\
\hline MG & MS & $100.00,00$ & $1.048,46$ & $104.846 .000,00$ & $73.392 .200,00$ & $7 \%$ & $5.137 .454,00$ \\
\hline MG & SC & $50.000,00$ & $1.048,46$ & $52.423 .000,00$ & $36.696 .100,00$ & $12 \%$ & $4.403 .532,00$ \\
\hline MG & PR & $30.000,00$ & $1.048,46$ & $31.453 .800,00$ & $22.017 .660,00$ & $12 \%$ & $2.642 .119,20$ \\
\hline MG & GO & $20.000,00$ & $1.048,46$ & $20.969 .200,00$ & $14.678 .440,00$ & $7 \%$ & $1.027 .490,80$ \\
\hline
\end{tabular}

Fonte: elaborado pelos autores

Para viabilizar essa possível proposta, o custo que a empresa terá com o transporte será de aproximadamente $\mathrm{R} \$ 23$ milhões de reais (valor embutido no preço de venda), podendo ainda obter crédito de ICMS sobre o frete das vendas de aproximadamente R\$ 2 milhões.

Vale ressaltar que o custo de transporte é um valor médio, esse valor muda de acordo com a região, oferta, demanda e período. Outro ponto a ressaltar é que o custo desse transporte é transferido do Rio Grande do Sul para Minas Gerais, pois a demanda dos Estados de Mato Grosso do Sul; Santa Catarina; Paraná e Goiás serão atendidas por Minas Gerais. Desta maneira a empresa deixaria de desembolsar o valor com transporte das vendas do Rio Grande do Sul para as UF's citadas acima. No quadro a seguir, a projeção do custo referente às vendas projetadas.

Quadro 9. Projeção custo e créditos de ICMS sobre Frete

\begin{tabular}{|l|l|l|l|l|l|l|}
\hline UF Origem & $\begin{array}{c}\text { UF } \\
\text { Destino }\end{array}$ & \multicolumn{1}{|c|}{ Quanti. } & $\begin{array}{c}\text { Preço Médio } \\
\text { Tonelada }\end{array}$ & \multicolumn{1}{|c|}{ Valor Total } & \multicolumn{1}{|c|}{$\begin{array}{c}\text { Alíquota } \\
\text { ICMS }\end{array}$} & \multicolumn{1}{|c|}{ ICMS } \\
\hline RS & MS & $100.00,00$ & 84,00 & $8.400 .000,00$ & $7 \%$ & $588.00,00$ \\
\hline RS & SC & $50.000,00$ & 174,00 & $8750.000,00$ & $12 \%$ & $1.050 .000,00$ \\
\hline RS & PR & $30.000,00$ & 135,00 & $4.050 .000,00$ & $12 \%$ & $486.000,00$ \\
\hline RS & GO & $20.000,00$ & 79,00 & $1.580 .000,00$ & $7 \%$ & $110.600,00$ \\
\hline
\end{tabular}

Fonte: elaborado pelos autores

Essa alternativa de efetuar as vendas por Minas Gerais, deve ser efetuada atentandose a outros fatores, tais como: disponibilidade de estoque nas unidades de Minas Gerais; disponibilidade de transporte nestas unidades; Mix de produtos disponíveis nas unidades de Minas Gerais; capacidade instalada das unidades de Minas Gerais; estratégia da empresa frente aos clientes e parceiros;

Para verificar se essa opção é aceitável para a empresa, é necessário realizar a projeção de venda do mesmo produto e em igual quantidade pelas unidades do Rio Grande do 
Sul. Considerando: Quantidades conforme projeção de vendas; Preço Médio por tonelada.

Quadro 10. Projeção Vendas Interestaduais Rio Grande do Sul parte 1

\begin{tabular}{|l|l|l|l|l|}
\hline UF Origem & UF Destino & Quantidade & Preço Médio/ Tonelada & Valor Total \\
\hline Rio Grande do Sul & Mato Grosso do Sul & $100.000,00$ & $1.209,03$ & $120.902 .500,00$ \\
\hline Rio Grande do Sul & Santa Catarina & $50.000,00$ & $1.086,03$ & $54.301 .250,00$ \\
\hline Rio Grande do Sul & Paraná & $30.000,00$ & $1.232,53$ & $36.975 .750,00$ \\
\hline Rio Grande do Sul & Goiás & $20.000,00$ & $1.286,53$ & $25.730 .500,00$ \\
\hline & & & Total Faturamento & $237.910 .000,00$ \\
\hline
\end{tabular}

Fonte: elaborado pelos autores

Na sequência a parte 2 da projeção de vendas interestaduais para o Rio Grande do Sul. Considerando: Alíquota ICMS

Quadro 11 - Projeção Vendas Interestaduais Rio Grande do Sul parte 2

\begin{tabular}{|l|l|l|l|l|l|l|}
\hline $\begin{array}{l}\text { UF } \\
\text { Origem }\end{array}$ & $\begin{array}{l}\text { UF } \\
\text { Destino }\end{array}$ & $\begin{array}{l}\text { Base de Cálculo ICMS } \\
\text { (Valor Total *70\%) }\end{array}$ & $\begin{array}{l}\text { Alíquota } \\
\text { ICMS }\end{array}$ & ICMS & $\begin{array}{l}\text { ICMS } \\
\text { Benefício Fiscal } \\
\text { (ICMS*75\%) }\end{array}$ & $\begin{array}{l}\text { Efetivo à } \\
\text { pagar }\end{array}$ \\
\hline RS & MS & $84.631 .750,00$ & $7 \%$ & $5.924 .222,50$ & $4.443 .166,88$ & $1.481 .055,63$ \\
\hline RS & SC & $38.010 .975,00$ & $12 \%$ & $4.561 .305,00$ & $3.420 .978,75$ & $1.140 .326,25$ \\
\hline RS & PR & $25.883 .025,00$ & $12 \%$ & $3.105 .963,00$ & $2.329 .472,25$ & $776.490,75$ \\
\hline RS & GO & $18.011 .350,00$ & $7 \%$ & $1.260 .794,50$ & $945.595,88$ & $315.198,63$ \\
\hline
\end{tabular}

Fonte: Elaborado pelos autores

Observou-se que as vendas efetuadas pelo Estado de Minas Gerais superou as vendas do Rio Grande do Sul pouco mais de R\$ 10 Milhões de reais. O ICMS superou aproximadamente R\$ 890 Mil reais. Porém para validar se realmente é viável essa alternativa é necessário um comparativo do custo do produto acabado dentro de cada unidade dos Estados em questão, conforme ilustrado no quadro a seguir.

Considerando: Quantidades conforme projeção de vendas - quadro 9; Preço Médio por tonelada e a Alíquota ICMS.

Quadro 12. Custos de aquisição

\begin{tabular}{|l|l|l|l|}
\hline UF Planta & Quantidade & Preço Médio/ Tonelada & Valor Total \\
\hline Minas Grais & $200.000,00$ & $1.048,46$ & $209.692 .000,00$ \\
\hline Rio Grande do Sul & $200.000,00$ & 872,03 & $174.405 .000,00$ \\
\hline Total Comparativo Custo Fabricação & & 176,44 & $35.287 .000,00$ \\
\hline
\end{tabular}

Fonte: elaborado pelos autores

Analisando este quadro, pode-se verificar que o custo de fabricação de Minas Gerais é R\$ 35 milhões superior ao custo de fabricação do Rio Grande do Sul. 
Na sequência foi realizado um comparativo entre as duas projeções, com a intenção de verificar qual é a menos onerosa para a empresa. Foram analisados os dados de Custo de fabricação, valor de frete, margem, e também a geração de débitos e créditos de ICMS incidentes na operação.

Quadro 13. Comparativo Vendas MG x RS

\begin{tabular}{|c|c|c|c|c|c|c|}
\hline $\begin{array}{c}\text { UF } \\
\text { Planta }\end{array}$ & $\begin{array}{c}\text { Faturamento } \\
\text { Total }\end{array}$ & $\begin{array}{c}\text { Custo } \\
\text { Fabricação }\end{array}$ & Frete & $\begin{array}{c}\text { Margem } \\
(a-b-c)\end{array}$ & $\begin{array}{c}\text { ICMS sobre } \\
\text { Vendas }\end{array}$ & $\begin{array}{l}\text { ICMS sobre } \\
\text { frete }\end{array}$ \\
\hline MG & $\begin{array}{l}248.012 .000,0 \\
0\end{array}$ & 209.692.000,00 & $22.780 .000,00$ & $\begin{array}{l}15.540 .000,0 \\
0\end{array}$ & $\begin{array}{l}15.739 .626,0 \\
0\end{array}$ & $2.234 .600,00$ \\
\hline RS & $\begin{array}{l}237.910 .000,0 \\
0\end{array}$ & $174.405 .000,00$ & $44.850 .000,00$ & $\begin{array}{l}18.655 .000,0 \\
0\end{array}$ & $3.713 .071,25$ & $3.814 .500,00$ \\
\hline Diferença & $10.102 .000,00$ & $35.287 .000,00$ & $\begin{array}{l}\text { (22.070.000,0 } \\
\text { 0) }\end{array}$ & $\begin{array}{l}\text { (3.115.000,0 } \\
\text { 0) }\end{array}$ & $\begin{array}{l}12.026 .554,7 \\
5\end{array}$ & $\begin{array}{l}(1.579 .900,0 \\
0)\end{array}$ \\
\hline \multirow{2}{*}{$\begin{array}{l}\text { Mercado X } \\
\text { mais } \\
\text { vantajoso }\end{array}$} & MG & & $x$ & & $x$ & \\
\hline & $\mathrm{RX}$ & $x$ & & $x$ & & $x$ \\
\hline
\end{tabular}

Fonte: elaborado pelos autores

Observa-se que apesar do frete ser mais oneroso para a venda do Rio Grande do Sul, o custo de fabricação do produto é relativamente menor se comparado ao custo de fabricação por Minas Gerais. Desta maneira, a margem sobre o faturamento do Rio Grande do Sul é cerca de R\$ 3 Milhões de reais superior a margem de Minas Gerais. A vantagem nessa projeção é que o saldo credor de ICMS acumulado em Minas Gerais seria reduzido, assim como o saldo devedor do Rio Grande do Sul.

\section{CONCLUSÃO}

O estudo objetivou investigar qual melhor forma da empresa pesquisa em utilizar seu saldo credor de ICMS. Em termos metodológicos, o estudo caracteriza-se como uma pesquisa exploratória e descritiva com abordagem qualitativa do problema. O levantamento dos dados deu-se por meio de documentos disponibilizados pela empresa e legislação do ICMS dos Estados onde a empresa possui unidades, tendo como base o ano de 2015.

Assim, estudou-se formas legais e de planejamento tributário para diminuição do saldo credor de ICMS acumulado. Depois de efetuados pesquisas bibliográficas, análises e cálculos, conclui-se que a alternativa menos onerosa para a empresa é a venda de saldo credor de ICMS acumulado para outras empresas. Desta maneira, a empresa vai gerar recursos para seu fluxo de caixa e, ao mesmo tempo, vai aumentar o retorno sobre o investimento realizado.

Diante desta situação defende-se o encontro de contas via administrativa entre devedores e credores do Imposto perante o fisco. Este encontro de contas, pode-se assim dizer, 
não é novidade na área judicial, onde muitas empresas adquirem precatórios - ordens judiciais de pagamento geradas pelas mais variadas situações - onde os governos estaduais não costumam honrar seus compromissos, para compensar com seu imposto devido.

Porém como alternativa ao encontro de contas, pode-se compensar ICMS, com ICMS. Portanto, se a empresa tem créditos de ICMS, nada mais coerente do que procurar gerar débitos do Imposto, com o objetivo de compensar o débito com o crédito acumulado do imposto em sua escrita fiscal, possibilitando assim a entrada destes recursos financeiros em seu caixa.

Isto é possível, desde que respeitando os limites impostos na Legislação e no Regulamento do ICMS, ou seja, efetuar esta compensação com a autorização e homologação do fisco, para evitar surpresas futuras.

Devido à amplitude do trabalho e a quantidade de documentos analisados alguns pontos não foram considerados no trabalho: não foram analisados os demais Estados que a empresa opera; não foram acrescentados na análise os créditos de Benefícios Fiscais específicos, estes gerados através de acordos entre a empresa e as Fazendas Estaduais; não foram abertos os créditos de entrada e débitos por Código Fiscal de Operação e Prestações (CFOP). Desta forma, é interessante que a empresa faça uma análise dos demais Estados para identificar oportunidades e ganhos tributários com um eficaz planejamento tributário.

\section{REFERÊNCIAS}

BRASIL, Lei complementar n. 87/96, de 13 de setembro de 1996: Dispõe sobre o imposto dos Estados e do Distrito Federal sobre operações relativas à circulação de mercadorias e sobre prestações de serviços de transporte interestadual e intermunicipal e de comunicação, e dá outras providências. Disponível em:

<http://www.planalto.gov.br/ccivil_03/leis/lcp/lcp87.htm>. Acesso em: 8 nov. 2019.

FABRETTI, L. C. Contabilidade tributária. 10. ed. São Paulo: Atlas, 2006.

FABRETTI, L. C. Direito tributário aplicado: impostos e contribuições de empresas. 2. ed. São Paulo: Atlas, 2012.

FARIA, R. A. C. Contabilidade tributária. Porto Alegre : SAGAH, 2016.

GAIL, P. A. R.; BARRETO, E. M. Tributação em debate: proposta de solução para o acúmulo de saldo credor de ICMS. Disponível em: <https://www.conjur.com.br/2015-mai-30/propostassolucoes-acumulo-saldo-credor-icms>. Acesso em: 5 set. 2019.

GASSEN, V. G.; D'ARAÚJO, P. J. S.; PAULINO, S. R. F. Tributação sobre Consumo: o esforço em onerar mais quem ganha menos. Sequência (Florianópolis), n. 66, p. 213-234, jul. 2013. Disponível em: <Doi: http://dx.doi.org/10.5007/2177-7055.2013v34n66p213>. Acesso em: 5 set. 2019. 
HUCK, H. M. Evasão e elisão: rotas nacionais e internacionais do planejamento tributário. São Paulo: Saraiva, 1997.

LIZOTE, S. A.; LANA, J. A Importância do Planejamento Tributário para a Lícita Redução dos Tributos e Otimização dos Lucros. In: IX Simpósio de excelência em gestão e tecnologia SEGet, 2012. Disponível em: <https://www.aedb.br/seget/arquivos/artigos12/1021676.pdf>. Acesso em 8 nov. 2019.

LOZAKAM, I. R. As diferenças hipóteses de saldo credo acumulado de ICMS, 2015. Disponível em: <http://artigoscheckpoint.thomsonreuters.com.br/a/6t54/as-diferentes-hipoteses-desaldo-credor-acumulado-de-icms-ivo-ricardo-lozekam>. Acesso em: 5 set. 2019.

MACHADO SEGUNDO, H. B. Código tributário nacional 7. ed. São Paulo: Atlas, 2018.

MACHADO SEGUNDO, H. B.; Curso de Direito Tributário. 34a Ed. Editora Malheiros, 2013.

MADRUGA, E. ICMS. In: OLIVEIRA, F. R.; GALLO, M. F. (Orgs.). Contabilidade e Gestão de Tributos. São Paulo: Editora Fiscosoft, 2015.

MARCONI, M. A. LAKATOS, E. M. Técnicas de pesquisa 8. ed. São Paulo: Atlas, 2018.

MARINS, J. Tributação e antielisão. Curitiba: Juruá, 2002.

MARTINS, G. A.; THEÓPHILO, C. R. Metodologia da investigação científica para ciências sociais aplicadas 3. ed. - São Paulo: Atlas, 2016.

MINAS GERAIS, Decreto no 46.919, de 28 de dezembro de 2015

(MG de 29/12/2015) Altera o Regulamento do ICMS (RICMS), aprovado pelo Decreto no 43.080, de 13 de dezembro de 2002, e dá outras providências.

<http://www.fazenda.mg.gov.br/empresas/legislacao_tributaria/decretos/2015/d46919_201 5.htm>. Acesso em 8 nov. 2019.

OLIVEIRA, G.P. Contabilidade Tributária. 3 ed. São Paulo: Saraiva, 2009.

PAIVA. P. A. S. A natureza jurídica da isenção tributária. REPATS, Brasília, V. 3, no 2, p. 330357, Jul. Dez, 2016. Acesso em: <file:///D:/Documentos/Downloads/7736-35441-1-PB.pdf>. Acesso em 12 nov. 2019.

PÊGAS. P. H. Manual de contabilidade tributária. 9. ed. - São Paulo: Atlas, 2017.

REZENDE, J. A.; PEREIRA, C. A.; ALENCAR, R. C. Contabilidade tributária: entendendo a lógica dos tributos e seus reflexos sobre os resultados das empresas. São Paulo: Atlas, 2010.

SOUSA, E. P. Contabilidade tributária: aspectos práticos e conceituais. São Paulo: Atlas, 2018. 